\title{
Relationship between the nutritional status and food consumption inside the school in adolescents of Mexico City
}

\author{
Rey Gutiérrez ${ }^{1}$, Claudia Radilla ${ }^{1}$, Salvador Vega ${ }^{1}$, Beatriz Schettino ${ }^{1}$, Jorge Ruíz ${ }^{2}$ and \\ María Radilla ${ }^{3}$ \\ ${ }^{1}$ Autonomous Metropolitan University Campus Xochimilco, Mexico City, Mexico, \\ ${ }^{2}$ Autonomous University of Chiapas, Chiapas, Mexico and \\ ${ }^{3}$ Foundation Aprende con Reyhan A.C., Mexico City, Mexico
}

\section{Abstract}

There is a concern that the bad habits and lifestyles of adolescents such as the consumption of foods rich in sugars and fats in free moments, like school recess acts as a factor that intervenes in the increase of weight. The aim of this study was to determine the relationship between the nutritional status and the food consumption inside the school in adolescents of Mexico City. A sample of 1457 first-grade adolescents from high schools was obtained. A food consumption frequency questionnaire was applied inside the school. Likewise, anthropometric measures were taken and through the use of Who Anthro Plus program, the nutritional status diagnosis was obtained. The obtained data was analyzed with the statistical package IBM SPSS Statistics ${ }^{\circledR}$ version 20.0 for Windows. It was found that adolescents who frequently consume sweets, snacks, flavored waters, bottled juices, confectionery products and ice cream have a higher prevalence of obesity $(15.2 \%, 17.4 \%, 21.4 \%, 17.7 \%, 16.2 \%$ and $19.9 \%$, respectively), compared to adolescents who never consume these products $(11.6 \%, 12.6 \%, 11.9 \%, 10.5 \%, 14.6 \%$, and $12.1 \%$, respectively). Likewise, it was found that adolescents who frequently consume fruit, water, yogurt, vegetables and milk have a lower prevalence of obesity $(10.2 \%, 12.2 \%, 10.3 \%, 10.1 \%$ and 9.35 , respectively) in comparison with adolescents who never consume these foods during school hours $(19.1 \%, 18.6 \%, 17.8 \%, 15.9 \%$ and $16.3 \%$, respectively), finding a highly significant difference $(\mathrm{p}<0.01)$ in the consumption of flavored water, fruit, natural water and yogurt. It was found that the food consumed during school hours has an impact on the nutritional status of adolescents, similar to the results found in the literature, so it is suggested to promote healthy habits and lifestyles at school and at home so that adolescents opt for healthy snack choices.

\section{Conflict of Interest}

There is no conflict of interest 